\title{
Olympic legacies and the sustainability agenda
}

\author{
Staging the Olympics now requires attention to sustainability and urban legacy. Resolving their competing \\ demands rests on recognizing the realities of the host city-IOC relationship.
}

\author{
John R. Gold and Margaret M. Gold
}

B y any standards 2020 ought to have been a vintage year for the global sporting and cultural jamborees now commonly termed 'mega-events'. After all, it was one of just five occasions in a century when the four-yearly cycle of the Summer Olympics and the five-yearly cycle of the International Expositions coincide. On 1 October Expo 2020 was scheduled to open in Dubai. Equally, the Games of the Thirty-Second Olympiad should have commenced in Tokyo ten weeks earlier on 24 July. Both, of course, were disrupted by the COVID-19 pandemic, but uncertainty over the future of Tokyo 2020 generated particularly intense debate. Critics pointed to the implications and opportunity costs of spending an estimated US $\$ 15.4$ billion ( $£ 11.5$ billion) on an event that might be cancelled or, at the very least, curtailed ${ }^{1,2}$. It also energized the debate over issues of legacy and sustainability that are now central when staging such events.

Concern for sustainability explicitly entered Olympic discourse in the 1990s. In 1994, the International Olympic Committee (IOC) decided that candidate cities for the Summer and Winter Games should have their plans formally evaluated on environmental grounds; a resolution matched by a decision to construe 'environment' as a 'third pillar' of the Olympic movement alongside 'sport' and 'culture. After amending the Olympic Charter in 1996 to uphold responsible concern for environmental issues, the IOC crafted its own Agenda 21 document in October 1999 as a "useful reference tool for the sports community at all levels in the protection of the environment and enhancement of sustainable development"3.

The idealistic tenor conveyed by these measures struck a genuinely resonant note within the Olympic movement itself not adverse to idealism - although the sustainability agenda arguably also addressed two other goals. First, it allowed the IOC to respond to accusations of 'gigantism', whereby it was blamed for requiring host cities to expend vast amounts of resources in constructing stadia and infrastructure for staging one-off events.

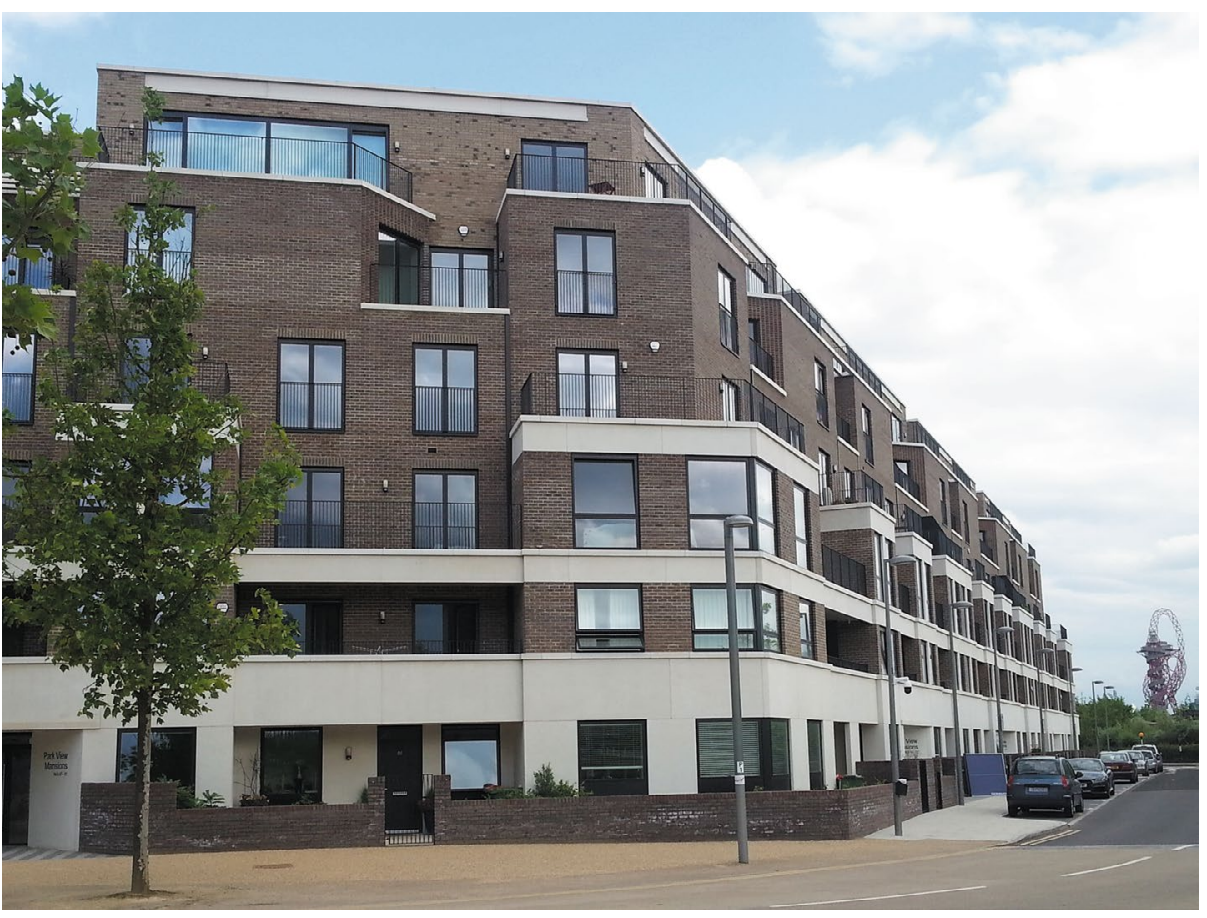

Fig. 1 | The post-Olympic city. The tangible legacy of London 2012 in the shape of apartment housing at Chobham Manor, a new neighbourhood built on land that pre-Games was mostly brownfield. Controversies continue as to the extent to which post-Olympic legacy housing, substantially sold at market value, meets broader standards for social sustainability.

Secondly, it served a strategic function. During the late 1970s and early 1980s, the lack of cities willing to bid for the Summer Games forced the IOC to acquiesce as host cities attached ever-larger urban interventions to the Games. This trend, which effectively started with Rome 1960, reached its apogee at Seoul 1988, when clearance of sites of dense housing (hanoks) in the urban core had forcibly displaced 720,000 people in order to create an Olympic Park, and Barcelona 1992, where the overwhelming bulk of investment (83\%) went on recreating the urban fabric rather than on the Games. Creation of frameworks for sustainability auditing and reports would serve at least to strengthen the IOC's hand when judging bids for the Games and give it a continuing voice during the development process.

\section{Legacy ascendant}

If sustainability led the way in renegotiating the core political relationship between host cities and the IOC that lies at the heart of the Olympic project, it was soon joined by a new concern for 'legacy" . Broadly considered as the sum total of the tangible and intangible outcomes arising from the event, urban legacy to date normally includes some mixture of flagship developments (such as constructing imposing stadia), major infrastructural schemes, and public realm improvements (for example, new parks and civic spaces), along with the lasting prestige of staging the event. Yet when consolidated thinking along legacy lines gained traction shortly after the turn of the millennium, it quickly revealed identifiable fissures between the views of the host cities and the Olympic movement. Legacy was itself 
a malleable concept. Partly by virtue of being only loosely defined and not tied to any specific time-horizon, it found favour amongst policymakers in actual or potential host cities. For them, it was a conveniently permissive framework within which they might choose to imagine, conceptualize, negotiate and realize the development trajectories of their Olympic projects. It would also increasingly serve as a filter through which sustainability was envisaged.

London 2012, the first Summer Games to be completed after the introduction of legacy thinking, was a case in point ${ }^{5}$. Analysis of its implementation reveals the extent to which legacy emerged as the central notion guiding post-Games transition. Legacy immediately translated into the visible transformation of East London, coupled with the notions that the investment, improved accessibility, and lasting aura of success associated with the Games had stimulated a seismic shift in the city's geography. By contrast, it was always likely that sustainability, often rooted in less-accessible conceptual and ethical arguments, would play a subsidiary role. These, after all, became popularly known as the 'Regeneration Games' ${ }^{6}$ and not the 'One Planet Games' as anticipated in the original bid. In the London experience, legacy was easier to sell, being represented as supplying tangible physical benefits for the city (Fig. 1). Sustainability, by contrast, was identified more as a technical matter and as part of the process by which legacy should be achieved?

\section{Agenda 2020 and after}

Taking stock of the situation, the IOC quickly responded with a series of documents that sought to place its own stamp on events. In 2014, it published Olympic Agenda 2020 ${ }^{\circ}$. Its 40 recommendations, inter alia, included measures to reduce the cost of bidding for and staging the Games, even holding out the prospect of joint bids by host cities to share expenditure. Associated strategies for sustainability and legacy emerged in 2016 and 2017, respectively. The sustainability strategy addressed a raft of matters, including the issue of venues (advocating temporary structures, reuse of existing facilities and sustainable design), infrastructure, local and global travel, movement of goods, and cutting greenhouse gases. The legacy strategy sought to embed legacy more firmly in the bidding phase, advocating that cities should have a clear vision $a b$ initio of the urban goals to be achieved throughout all stages of hosting of the Games.

These documents, along with further tweaking of Olympic Agenda 2020 in 2018 and 2021, shifted thinking away from imposing a set of strict conditions on host cities to allowing greater flexibility to suit the city's needs and existing facilities ${ }^{9}$. Potential cost savings might stem from further changes to the bidding process, moving away from the expectations regarding the size, spread and provision of new structures, instead encouraging temporary venues and the reuse of venues where possible, promoting greater flexibility in the design of Athletes' Villages for legacy use, and greater emphasis on public transport. It was calculated on a conceptual basis that a saving of up to US\$959 million would accrue for a summer Games, of which US\$134 million was due to reduced costs of Games governance and US\$731 million for Games requirements ${ }^{10}$. Moreover, it was hoped that these changes would encourage bidding for the Games from a wider spread of cities in terms of both size and location.

This last point was of major concern by 2020 . For the second time in 40 years, the supply of potential cities to bid for the Summer Games had dried up. When the final bidding process for the 2024 Summer Games was completed in 2017, the IOC was left with just two candidate cities - Paris and Los Angeles - a repeat of the same problem manifested itself with the Winter Games in 2015 when the IOC found itself faced with just two candidates - Beijing and Almaty (Kazakhstan) - neither of which were seen as ideal choices. Yet again in 2019 only two cities were in the race for the 2026 Winter Games (Milan and Stockholm). Hence while pragmatic in light of the circumstances, the IOC's efforts in promoting action for sustainability and legacy need to be judged against the real reasons why cities seek the Games in the first place. The Olympics have achieved their extraordinary staying power - a sequence that since 1896 has been broken only by the two World Wars - because host cities are willing to shoulder the financial burden. Latitude to pursue agendas linked to regeneration, urban restructuring, national brand formation, infrastructure renewal and the kudos of staging a globally prestigious event have powered that process. Inevitably it is only by working with the grain of the host city-IOC relationship that any future marriage of mega-event and sustainability will be achieved.

John R. Gold ${ }^{1 凶}$ and Margaret M. Gold ${ }^{2}$ ${ }^{1}$ Department of Social Sciences, Oxford Brookes University, Oxford, UK. ${ }^{2}$ London Metropolitan University, London, UK.

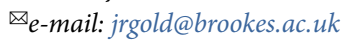

Published online: 20 April 2021

https://doi.org/10.1038/s41893-021-00711-9

References

1. Holthus, B., Gagné, I., Manzenreiter, W. \& Waldenberger, F. (eds) Japan Through the Lens of the Tokyo Olympics (Taylor \& Francis, 2020).

2. Boykoff, J. \& Gaffney, C. Capital. Nat. Social. 31, 1-19 (2020).

3. Olympic Movement's Agenda 21: Sport for Sustainable Development (International Olympic Committee, 2006).

4. Booth, D. Int. Rev. Sociol. Sport 46, 367-386 (2011).

5. Gold, J. R. \& Gold, M. M. Geogr. Compass 2, 300-318 (2008).

6. Evans, G. Archit. Res. Q. 18, 353-366 (2014).

7. Gold, J. R. \& Gold, M. M. Revue STAPS 37, 23-35 (2014).

8. Olympic Agenda 2020: 20+20 Recommendations (International Olympic Committee, 2014).

9. Schnitzer, M. \& Haizinger, L. Sustainability 11, 442 (2019).

10. The New Norm: Candidacy Delivery Legacy (International Olympic Committee, 2018).

Competing interests

The authors declare no competing interests. 